\title{
Perceptions of genetic risk, testing, and counseling among individuals with eating disorders
}

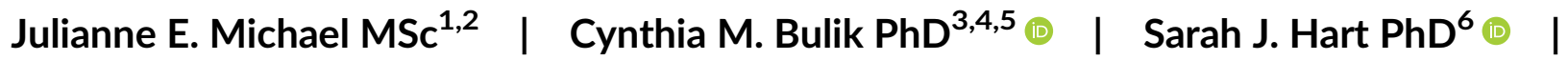 \\ Lauren Doyle $\mathrm{MGC}^{1}$ । Jehannine Austin $\mathrm{PhD}^{7}$
}

${ }^{1}$ Genetic Counseling Program, University of North Carolina at Greensboro, Greensboro, North Carolina

${ }^{2}$ Department of Medical Genetics and Genomics, Spectrum Health Helen DeVos Children's Hospital, Grand Rapids, Michigan

${ }^{3}$ Department of Psychiatry, University of North Carolina School of Medicine, Chapel Hill, North Carolina

${ }^{4}$ Department of Nutrition, University of North Carolina Gillings School of Global Public Health, Chapel Hill, North Carolina

${ }^{5}$ Department of Medical Epidemiology and Biostatistics, Karolinska Institutet, Stockholm, Sweden

${ }^{6}$ Department of Pediatrics, Duke University Medical Center, Durham, North Carolina

${ }^{7}$ Departments of Psychiatry and Medical Genetics, BC Mental Health and Substance Use Services Research Institute, University of British Columbia, Vancouver, British Columbia, Canada

\section{Correspondence}

Lauren Doyle, Genetic Counseling Program, University of North Carolina at Greensboro, 996 Spring Garden St, Greensboro, NC 27412. Email: ledoyle2@uncg.edu

Jehannine Austin, Departments of Psychiatry and Medical Genetics and BC Mental Health and Substance Use Services Research Institute, University of British Columbia, Rm A2-127, 938 W28th Ave, Vancouver, BC V5Z4H4.

Email: jehannine.austin@ubc.ca

Action Editor: Ruth Weissman

Funding information

BC Mental Health and Substance Use Services; Canada Research Chairs; National Eating Disorders Association; National Society of Genetic Counselors'

\begin{abstract}
Objective: Eating disorders develop as a result of genetic and environmental factors. Given that they are multifactorial conditions with a genetic component, they fall within the scope of practice for genetic counseling, but people with these conditions are rarely referred. The purpose of this study was to explore the perceptions of causes of eating disorders, recurrence risk, and interest in genetic counseling and testing among individuals with eating disorders.

Method: An online survey comprising both multiple choice and free form text questions, vignettes about genetic counseling, and the ED100K (validated eating disorder diagnostic questionnaire) was shared via support organizations and prominent bloggers in the eating disorders community to recruit individuals with a personal history of an eating disorder from November 2018 to February 2019.

Results: In total, 107 participants completed the survey. They perceived that both experiences and genetics were important factors in the development of their eating disorder. All responding participants overestimated the risk for recurrence of eating disorders in children, often by a large margin, and a notable minority reported that their experience with an eating disorder had a negative influence on their childbearing decisions. After imagined experience of genetic counseling, participants reported significantly decreased feelings of stigma, shame, and guilt. Most participants expressed interest in genetic counseling; fewer were interested in genetic testing.

Discussion: Genetic counseling may benefit individuals with eating disorders by providing accurate recurrence risk information and reducing feelings of guilt, stigma, and shame, which may in turn encourage earlier support seeking and recovery.
\end{abstract}

\section{KEYWORDS}

anorexia nervosa, binge eating; eating disorders, bulimia, genetic counseling, genetic testing, genetics, recurrence risk, stigma 


\section{1 | INTRODUCTION}

\section{1 | Eating disorders}

Eating disorders are currently considered to be among the most fatal of mental illnesses (Arcelus, 2011). These conditions are complex in etiology, developing from a combination of genetic and environmental factors (Fairburn \& Harrison, 2003). However, they are frequently perceived as being subject to voluntary control, which can result in blame, dislike, and anger toward individuals with eating disorders (Crisafulli, Von Holle, \& Bulik, 2008). The social stigma and perception that eating disorders are a choice (Easter, 2014) are main barriers to social support seeking among individuals with eating disorders (Akey, Rintamaki, \& Kane, 2013; Becker, Hadley Arrindell, Perloe, Fay, \& Striegel-Moore, 2010).

\section{2 | Genetics and eating disorders}

Twin-based heritability estimates have ranged from 48 to $74 \%$ for anorexia nervosa, $55-62 \%$ for bulimia nervosa, and $39-45 \%$ for binge-eating disorder (Bulik, Yilmaz, \& Hardaway, 2015). Studies have shown that first-degree relatives of individuals with anorexia nervosa have a 4-11.3-fold risk over the general population of developing anorexia nervosa and those with a first-degree relative with bulimia nervosa have a 4.4-9.6-fold risk (Bulik et al., 2015; Steinhausen, Jakobsen, Helenius, Munk-Jørgensen, \& Strober, 2015; Strober, Freeman, Lampert, Diamond, \& Kaye, 2000; Thornton, Mazzeo, \& Bulik, 2010). More recently, studies have begun to identify specific genomic variants that influence vulnerability to eating disorders (Duncan et al., 2017; Watson et al., 2019). Ultimately, eating disorders-as complex conditions that involve a genetic contribution-fall within the range of conditions that can usefully be addressed within the scope of genetic counseling.

\section{3 | Genetic counseling}

Genetic counseling has been defined by the National Society of Genetic Counselors as "the process of helping people understand and adapt to the medical, psychological, and familial implications of the genetic contributions to disease. This process integrates: interpretation of family and medical histories to assess the chance of disease occurrence or recurrence; education about inheritance, testing, management, prevention, resources, and research; and counseling to promote informed choices and adaptation to the risk or condition" (Resta et al., 2006). Genetic counseling for psychiatric disorders has been shown to have positive outcomes (Austin \& Honer, 2008; Hippman et al., 2016; Inglis, Koehn, McGillivray, Stewart, \& Austin, 2015; Moldovan, Pintea, \& Austin, 2017; Semaka \& Austin, 2019) but is still an underutilized service (Hunter, Hippman, Honer, \& Austin, 2010; Moldovan et al., 2019). To shed light on potential explanations for this, previous studies have explored interest in genetic counseling among other populations impacted by mental illnesses (Andrighetti et al., 2016; Austin \& Honer, 2008; Austin, Smith, \& Honer, 2006; DeLisi \& Bertisch, 2006; Erickson et al., 2014; Kalb, Vincent, Herzog, \& Austin, 2017; Lyus, 2007; Meiser et al., 2008; Meiser, Mitchell, McGirr, Van Herten, \& Schofield, 2005; Quaid, Aschen, Smiley, \& Nurnberger, 2001; Quinn et al., 2014; Wilhelm et al., 2009), but none have looked specifically at attitudes of individuals with eating disorders.

\subsection{Purpose of the present study}

The purpose of this study was to assess the perceptions of individuals with eating disorders regarding: causation of eating disorders, chances for children to develop eating disorders, effect of having an eating disorder on childbearing decisions, and the utility of genetic counseling and genetic testing. Furthermore, based on the existing literature, we hypothesized that after considering hypothetical scenarios of receiving genetic counseling for their eating disorder, participants would anticipate decreased feelings of guilt, shame, stigmatization, being looked down upon, and being treated differently.

\section{2 | METHODS}

\subsection{Participants and recruitment}

Participants were recruited via online forums and support organizations (including Project HEAL and NEDA, and via bloggers with high visibility within the eating disorder community who shared information about the study). Recruitment invitations included an opening message and a link to the survey. Between November 2018 and February 2019, we recruited individuals aged 18-65 with a self-reported personal history of an eating disorder. The study was approved by the University of North Carolina-Greensboro Institution Review Board (19-0083).

\subsection{Survey tool}

Participants completed an online survey (hosted by Qualtrics) that we adapted (see supplemental material for the complete survey) from Kalb et al. (2017) that assessed factors including demographics; personal and family history of eating disorders, including specific subtype of the individual's eating disorder using the ED100K (Thornton et al., 2018); past genetic counseling experiences and whether their eating disorder was addressed during those encounters; perceived causation of eating disorders; perception of recurrence risk; the impact of having an eating disorder on family planning decisions; potential interest in genetic testing and genetic counseling for eating disorders. Perceptions of eating disorder causation were assessed using a visual analog scale (participants could move a slider to indicate how much [0-100\%] they thought their eating disorder was caused by genetic or experience-based factors). 
To test the hypotheses (see purpose section), first, participants were asked to use a visual analog scale to indicate how guilty, ashamed, stigmatized, looked down upon, and differently treated they felt as a result of having an eating disorder. Then, each participant was presented with two vignettes (adapted from Andrighetti et al., 2016; see Box 1) that depicted two different elements of genetic counseling-specifically, counseling around eating disorder etiology (a fundamental component of the genetic counseling encounter, Vignette 1), and counseling around risks for recurrence and risk reduction strategies (an important component of genetic counseling that is provided for specific patients as indicated, Vignette 2). All participants read the vignettes in the same order (an order that reflects the sequence in which these topics would be addressed clinically), and after reading both, were presented a visual analog scale (identical to the one they completed prior to reading the vignettes) and asked to imagine that they had participated in the interaction with a genetic counselor as described in the vignettes, and to move each slider to reflect how they would feel now about having an eating disorder. classifiable. A free form text field was also provided for participants to describe their thoughts on the potential benefits and risks of genetic testing for eating disorders, responses provided in this field were handled in the same way. For all categorizations of free form text data, any discrepancies in how responses were classified were discussed until consensus between coders was reached. Quotes were chosen to provide illustrative context for key categories.

\section{3 | Analysis}

Descriptive statistics including frequency distributions, means and standard deviations, and proportions were calculated. Eating disorder diagnoses were determined from responses to the ED100K using algorithms in SAS, Version 9.4. Nonparametric $t$ tests were used to examine our hypotheses about perceived differences in feelings of being treated differently, being looked down upon, guilt, stigma, and shame by comparing mean pre- and postvignette scores for the whole sample.

\section{BOX 1}

Vignette 1: Sarah has an eating disorder. She has questions about what causes eating disorders, so she visits a genetic counselor. The genetic counselor first asks her about what she thinks causes an eating disorder to develop. The counselor then talks with her about how common it is for individuals to feel guilty about having an eating disorder; but how it is not someone's fault if they have an eating disorder. The counselor talks about how eating disorders are caused by a mix of a person's genes and environment, and that there are many genes involved in determining risk for developing an eating disorder, but eating disorders are not determined solely by genetics. Experiences that we have, like being exposed to environments that emphasize thinness, teasing, or bullying about shape and weight, also influence whether or not we develop an eating disorder. There is no single factor that is sufficient to cause the development of an eating disorder. The counselor emphasizes that eating disorders are not a moral failing or anyone's fault. The genetic counselor and Sarah then discuss together the importance of identifying signs of eating disorders early and getting help.

Vignette 2: Sarah wants to know what the likelihood is of someone else in her family developing an eating disorder. The genetic counselor takes a careful family history and asks Sarah about her mental health as well as that of her family members and uses this information to estimate that someone in her family has a chance to develop an eating disorder of about $15 \%$, or about 3 in 20 . They talk about how this compares to the general population risk for an eating disorder of about 3.5\%, or about 1 in 30 , and the genetic counselor then asks Sarah how she feels about this chance. They then talk about some strategies to reduce risk and protect mental health for both Sarah and her family members, including things like getting an adequate amount of sleep every night, having good nutrition, seeking out social support, creating open space to talk about mental health in general and more specific topics like weight and shape concerns and body-esteem, and finding effective ways to manage stress. The genetic counselor emphasizes that these can be difficult things to do well consistently, and that it is important to just do what you can and be kind to yourself about imperfection.

In addition, to begin to gather information about elements of the genetic counseling session that participants felt would be useful, they were provided with a free form text field for each vignette to explain whether or not they thought the elements of genetic counseling it described would be useful. Text entered in these fields was independently coded by two members of the study team (JA and JS), and responses were categorized as reflecting that the participant felt that the genetic counseling described was (a) useful, (b) not useful, if the participant was (c) unsure and/or felt that the usefulness was dependent on circumstances, or (d) if the response was not readily
Statistical significance for testing our hypotheses was assumed at $p<.01$ after Bonferroni correction to account for our five statistical tests, all of which were carried out using SPSS Software, Version 25.

In addition to hypothesis testing, we also conducted exploratory analyses: Spearman's rho was used to evaluate correlations between perceived genetic causation and (a) concern for children and (b) perceived interest in genetic counseling, and $t$ tests were used to evaluate correlations between perceived genetic causation and family history of eating disorders and between childbearing decisions and perceived probability of illness recurrence in children. 


\section{3 | RESULTS}

\section{1 | Demographics}

We received a total of 107 responses, all of which were included in the analysis. The mean age of our participants was 31.7 (range $=18-63$, $S D=11.3$ ). Other demographic information is presented in Table 1.

\subsection{Perception of causes of eating disorders}

Overall, participants reported perceiving that their experiences and genetics accounted for 68.3 and $45.1 \%$, respectively, of the contribution to their eating disorder (these percentages do not add up to $100 \%$ as perceptions of the contributions of genetics and experiences were assessed separately).

\section{3 | Perception of risk for recurrence}

Participants' perceptions of the chance for the sons and daughters of people with eating disorders to develop the same condition are shown in Table 2. As compared to the 3-12\% empiric risk for eating disorder recurrence (Thornton et al., 2010), all responding participants overestimated the chance for a daughter to develop an eating disorder, and $95 \%$ overestimated the chance for sons-with the remaining 5\% estimating the chance for sons correctly.

\subsection{Effects of having an eating disorder on childbearing decisions}

Participants most frequently reported that they did not know how having an eating disorder would influence childbearing decisions as they were not yet ready for children ( $n=37 ; 43.5 \%$ ). Of the remainder, most participants ( $n=33,38.8 \%$ ) reported that their eating disorder did not influence their decision to have children, with smaller groups reporting choosing not to have children, or to adopt or have fewer children ( $n=12,14.1 \%$, and $n=3,3.6 \%$ respectively) as a result of their eating disorder. Most participants reported a self-rated level of concern for daughters to develop an eating disorder at moderately-to-extremely concerned (66.3\%), but only reported being somewhat-to-moderately concerned (62.6\%) about a son developing an eating disorder. Participants self-rated levels of concern are shown in Table 2.

\subsection{Interest in genetic counseling and testing}

Slightly less than half of participants reported being interested personally in genetic testing for their eating disorder (47\%). Participants'
TABLE 1 Demographic characteristics

\begin{tabular}{|c|c|}
\hline Variable & $N(\%)$ \\
\hline \multicolumn{2}{|l|}{ Gender } \\
\hline Female & $96(93)$ \\
\hline Male & $4(4)$ \\
\hline Other (trans/genderqueer) & $3(3)$ \\
\hline \multicolumn{2}{|l|}{ Sex } \\
\hline Female & 99 (96) \\
\hline Male & $4(4)$ \\
\hline \multicolumn{2}{|l|}{ Education level } \\
\hline High school or less & $24(24)$ \\
\hline Associate's degree or trade school & $9(9)$ \\
\hline Bachelor's degree & $35(34)$ \\
\hline Master's degree & $25(24)$ \\
\hline $\mathrm{PhD}$ degree & $5(5)$ \\
\hline MD or DO degree & $4(4)$ \\
\hline \multicolumn{2}{|l|}{ Race } \\
\hline Caucasian & $95(91)$ \\
\hline Mixed & $3(3)$ \\
\hline African American & $2(2)$ \\
\hline Native Hawaiian or Pacific islander & $1(1)$ \\
\hline American Indian or Alaska native & $1(1)$ \\
\hline Unknown & $1(2)$ \\
\hline \multicolumn{2}{|l|}{ Ethnicity } \\
\hline Hispanic or Latino & $4(4)$ \\
\hline Not Hispanic or Latino & $99(96)$ \\
\hline \multicolumn{2}{|l|}{ Marital status } \\
\hline Married & $34(33)$ \\
\hline Divorced & $4(4)$ \\
\hline Separated & $2(2)$ \\
\hline Cohabitating & $10(10)$ \\
\hline Significant other, not cohabitating & $11(10)$ \\
\hline Single & $42(41)$ \\
\hline \multicolumn{2}{|l|}{ Children } \\
\hline Yes & $23(22)$ \\
\hline No & $80(78)$ \\
\hline \multicolumn{2}{|l|}{ Eating disorder } \\
\hline Anorexia nervosa & $57(53)$ \\
\hline Bulimia nervosa & $25(29)$ \\
\hline Binge-eating disorder & 19 (18) \\
\hline \multicolumn{2}{|l|}{ Comorbid psychiatric disorders } \\
\hline Yes & $78(76)$ \\
\hline No & $25(24)$ \\
\hline \multicolumn{2}{|l|}{ Family history of eating disorders } \\
\hline Yes & $37(41)$ \\
\hline No & $53(59)$ \\
\hline
\end{tabular}


TAB LE 2 Estimated probability and concern for children to develop an eating disorder

\begin{tabular}{|lcc|}
\hline & Daughter & \multicolumn{1}{l|}{ Son } \\
\hline $\begin{array}{l}\text { Estimated probability for child of } \\
\text { person with eating disorder to }\end{array}$ & $57.6(15-$ & $43.0(8-$ \\
develop eating disorder too M & $100: 18.8)$ & $85: 17.3)$ \\
(range: $S D$ ) & & \\
Level of concern for children to develop an eating disorder N (\%) \\
Not at all concerned & $7(6.5)$ & $4(3.7)$ \\
Somewhat & $8(7.5)$ & $38(35.5)$ \\
Moderately & $33(30.8)$ & $29(27.1)$ \\
Extremely & $38(35.5)$ & $15(14.0)$ \\
\hline
\end{tabular}

Note: Eighty-six participants overestimated the probability of a daughter developing an eating disorder, and 82 overestimated the probability for a son.

own interest in genetic testing, if it were to become available, and their perceptions of their family members' potential interest is shown in Figure 1. Perceptions of the potential benefits and risks associated with genetic testing for eating disorders reported by participants are included in Table 3. Of those who provided classifiable responses in the freeform text fields, the greatest proportion of participants ( $n=25,46 \%$ ) identified only benefits; 17 (32\%) identified only risks; and $12(22 \%)$ identified benefits and risks.

Most participants ( $n=62 ; 57.9 \%$ ) had heard of genetic counseling. Of the eight (7.5\%) who had received genetic counseling (related to cancer or for genetic testing), two (1.9\%) reported discussing their eating disorder during the genetic counseling appointment.

After reading the two vignettes about genetic counseling for eating disorders, most participants ( $n=66,61.7 \%$ ) reported some degree of interest in receiving the sort of genetic counseling depicted. For vignettes 1 and 2, 75 and 72 participants respectively provided written comments in the free form text field. For both vignettes 1 and 2 , most participants ( $n=45,60 \%$, and $n=40,55.5 \%$, respectively) felt the intervention described would be useful. In both scenarios, some participants ( $n=22,29.4 \%$, and $n=21,29.2 \%$, respectively) thought that whether or not it would be useful would be dependent on other factors. Finally, a minority of participants $(n=4,5.3 \%$, and $n=8$, $11.1 \%$, respectively) thought the intervention described would not be useful. Illustrative quotes for each of these categories of responses are provided in Table 4.

\subsection{Anticipated reactions to genetic counseling}

Participants reported decreased feelings of being treated differently, guilt, being looked down upon, shame, and stigmatization as a result of imagining meeting with a genetic counselor to discuss their eating disorder. Means for pre- and postimagined experience are shown in Figure 2. All decreases were statistically significant $(t(78)=4.83, p<.001$ treated differently; $t(77)=5.88, p<.001$ guilt; $t(77)=3.85, p<.001$ looked down upon; $t(79)=6.22, p<.001$ shame; $t(77)=4.22, p<.001$ stigmatized) with effect sizes ranging from small to moderate ( $d=0.3$ for stigma

\section{Personal Interest in Genetic Testing}

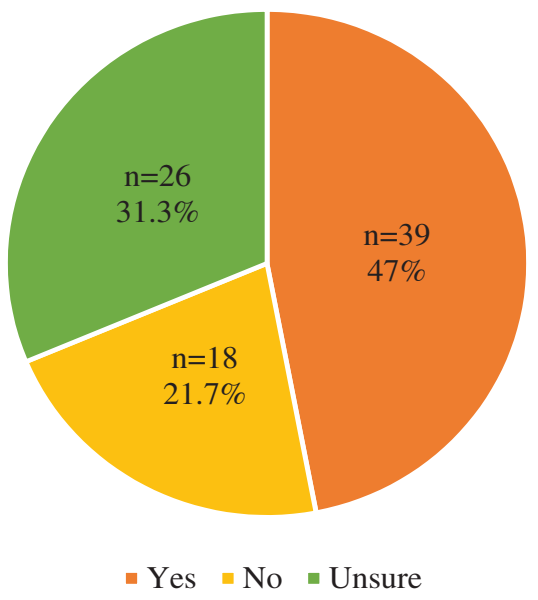

Perceived Family Member Interest in Genetic Testing

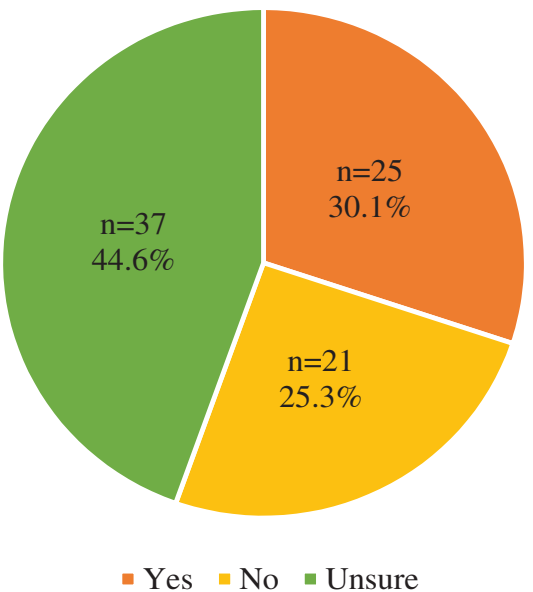

FIGURE 1 Interest in Genetic Testing for Eating Disorders. Participants responded to the questions: If genetic testing were available that could help determine the risk of developing an eating disorder, do you think you would be interested in pursuing such testing? Yes, No, Unsure. If genetic testing were available that could help determine the risk of developing an eating disorder, do you think your family members would be interested in pursuing such testing? Yes, No, Unsure [Color figure can be viewed at wileyonlinelibrary.com]

and being looked down upon, $d=0.44$ for being treated differently), to moderate to large ( $d=0.6$ for guilt and shame).

\section{7 | Exploratory analyses}

In exploratory analyses, we found no significant relationships between participants' perceptions of the contribution of genetics to the etiology of eating disorders and

- whether or not they had a family history of an eating disorder (mean perceived contribution of genetics: among those with a 
TABLE 3 Benefits and risks of genetic testing for eating disorders

\begin{tabular}{|c|c|c|c|}
\hline & Theme & $N$ & Illustrative quote \\
\hline \multirow[t]{4}{*}{ Benefits } & $\begin{array}{l}\text { Preventive measures/early } \\
\text { intervention }\end{array}$ & 24 & $\begin{array}{l}\text { I think a benefit would be getting treatment early on when signs are starting to appear, being } \\
\text { conscious of the signs and symptoms, and taking preventative measures. }\end{array}$ \\
\hline & Reducing guilt/stigma & 6 & $\begin{array}{l}\text { More focus on the biological components could be helpful in reducing stigma and getting more } \\
\text { relevant help-there are only so many "if a Barbie were a real woman ..." scenarios a girl can sit } \\
\text { through before it starts to feel like people are really missing the point. }\end{array}$ \\
\hline & Reducing anxiety & 1 & $\begin{array}{l}\text { I think it would put some people's minds more at ease about having children and might provide } \\
\text { closure about how their eating disorder developed }\end{array}$ \\
\hline & $\begin{array}{l}\text { Potential for better } \\
\text { treatments }\end{array}$ & 1 & It could help develop more effective treatment of eating disorders from a research perspective. \\
\hline \multirow[t]{5}{*}{ Risks } & Fatalism/false reassurance & 18 & $\begin{array}{l}\text { A positive result could lead to years of being so consumed waiting for the illness to strike that you } \\
\text { stop living long before you become unwell. A negative result could lead to ambivalence and } \\
\text { dismissal of signs, for example, if a person goes throughout a traumatic event and develops an ED } \\
\text { as a means to cope but was told they had no risk factors they would not seek help because they } \\
\text { think they are immune. }\end{array}$ \\
\hline & Increased anxiety & 13 & $\begin{array}{l}\text { I imagine, for myself as a child, that a hyperfocus on avoiding an eating disorder would initiate the } \\
\text { perfectionistic elements of my personality and overwhelm me with the need to "do it right," thus } \\
\text { propelling a focus on food and weight where one might not have been before. }\end{array}$ \\
\hline & $\begin{array}{l}\text { Increasing stigma/ } \\
\text { discrimination }\end{array}$ & 5 & I would be worried that it could impact insurance coverage. \\
\hline & Access inequality & 1 & $\begin{array}{l}\text { That this testing would only be available to people who have the money to pay for it, and would } \\
\text { therefore exclude many vulnerable populations }\end{array}$ \\
\hline & Increasing guilt/shame & 1 & $\begin{array}{l}\text { Some risks could be ... people experiencing even more shame if they took counseling, engaged in } \\
\text { prevention efforts, yet still developed eating disorders. }\end{array}$ \\
\hline
\end{tabular}

Note: Participants responded to the question: "What do you see as the benefits and risks associated with genetic testing becoming available that could help determine the risk of developing an eating disorder?"

TA B LE 4 Perceived utility of genetic counseling for eating disorders

\begin{tabular}{|c|c|c|c|}
\hline & Category & $N(\%)$ & Illustrative quote \\
\hline \multirow[t]{4}{*}{$\begin{array}{l}\text { Vignette } \\
1\end{array}$} & Useful & $45(60)$ & $\begin{array}{l}\text { Wow just reading this validated so many things I felt, like that it is genes and environment and that guilt } \\
\text { is so common in people with eating disorders, I feel like people need to hear and understand this- } \\
\text { people with eating disorders and the public }\end{array}$ \\
\hline & $\begin{array}{l}\text { Unsure/ } \\
\text { depends }\end{array}$ & 22 & $\begin{array}{l}\text { I do not think having a discussion about the early signs of eating disorders would be helpful for someone } \\
\text { who already has one. I think the usefulness of the conversation would also depend on (a) the } \\
\text { knowledge Sarah had before going into the conversation, (b) the extent to which Sarah felt ashamed, } \\
\text { stigmatized, etc. for having an eating disorder, and (c) how open she was to reframing her opinions/ } \\
\text { judgments of herself }\end{array}$ \\
\hline & Not useful & $4(5.3)$ & I would not believe what they were saying. I'd think it's still my fault \\
\hline & Not classifiable & $4(5.3)$ & $\begin{array}{l}\text { I feel genetics can give us a predisposition to developing an eating disorder but it is our circumstances } \\
\text { that would be the catalyst }\end{array}$ \\
\hline \multirow[t]{4}{*}{$\begin{array}{l}\text { Vignette } \\
2\end{array}$} & Useful & 40 & $\begin{array}{l}\text { This information would be so useful. For me, I'm terrified that my child may get an eating disorder. To } \\
\text { have the information provided and strategies in place to help reduce that risk would be so comforting. }\end{array}$ \\
\hline & $\begin{array}{l}\text { Unsure/ } \\
\text { depends }\end{array}$ & $\begin{array}{l}21 \\
(29.2)\end{array}$ & $\begin{array}{l}\text { As a pregnant woman this is what I want to know about for my child so that I can be even more } \\
\text { intentional, open and authentic in how I raise them. I'm not sure how this would sit for me as me now } \\
\text { though. Though I know it is not my fault I think I would almost make an association away from } \\
\text { genetics and as though my eating disorder causes others in my family to have them. Though } \\
\text { recovered me knows that's irrational. }\end{array}$ \\
\hline & Not useful & $8(11.1)$ & $\begin{array}{l}\text { I just do not see the point. If she already has the eating disorder, who cares what her risk factor is? I } \\
\text { mean, I love the idea of giving concrete strategies to be on the lookout for, for her and her family, I } \\
\text { just do not understand why she has to know the genetic component as long as she's treating her } \\
\text { eating disorder. } \\
\text { I would think that this is not useful because it puts pressure on the individual with an eating disorder to } \\
\text { care for her family and prevent eating disorders in them. That should not be her responsibility. }\end{array}$ \\
\hline & Not classifiable & $3(4.2)$ & The genetic counselor sounds very knowledgeable. \\
\hline
\end{tabular}




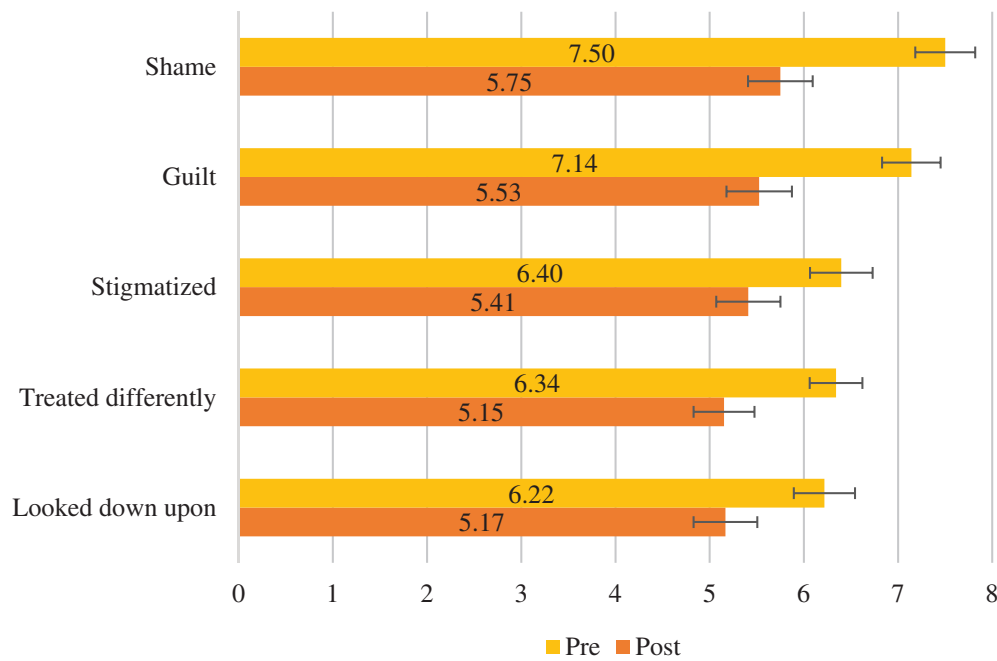

FIGURE 2 Participants anticipated reactions to receiving genetic counseling. Prior to reading the vignettes about genetic counseling participants were asked to move a slider for each item to reflect how they felt about having an eating disorder. After reading the vignettes, participants were asked to imagine that they had had the interaction with a genetic counselor as described, and to move each slider for each item to reflect how they would now feel about having an eating disorder [Color figure can be viewed at wileyonlinelibrary.com] family history $=49.8 \%$, among those without a family history $=41.6 \%, t[80]=1.84, p=.07), d=0.4$.

- concern about recurrence of eating disorders in their children (concern about daughters: Spearman's rho $=0.205, p=.06$, sons: Spearman's rho $=0.181, p=.09$ ).

- interest in genetic counseling (Spearman's rho $=0.157, p=.16$ ).

We also found no relationship between perceived risk for children to develop eating disorders and participants' reported childbearing decisions. Among those who reported planning to have fewer or no children and those who reported their eating disorder had not changed their plans for children, mean perceived risks for daughters were $64(S D=21)$ and $58 \%(S D=17)$, respectively $(t[46]=1.05, p=.2)$, and for sons, estimates were $48 \%(S D=17)$ and $45 \%(S D=15)$, respectively $(t[46]=0.59, p=.5)$.

\section{4 | DISCUSSION}

This was the first study, to our knowledge, to investigate perceptions of cause of illness, risk for recurrence, and interest in genetic counseling and testing among individuals with an eating disorder. While less than half of our participants were personally interested in having genetic testing, two-thirds were interested in receiving genetic counseling for their eating disorder. After reading vignettes about and imagining having received genetic counseling, participants anticipated significant reductions in feelings of guilt, stigma, shame, feeling differentially treated, and feeling looked down upon. Data from previous studies suggest that our participants' anticipated outcomes of genetic counseling may be realistic-specifically, in the context of other psychiatric conditions, genetic counseling has been shown to reduce stigma and shame, and to increase empowerment (Austin \& Honer, 2004, 2007, 2008; Costain et al., 2014; Inglis et al., 2015; Semaka \& Austin, 2019). Given that people with eating disorders report avoiding or postponing seeking or using treatment because of stigma and shame (Becker et al., 2010), and/or guilt and the belief that they should be able to help themselves (Thompson \& Park, 2016), this finding could suggest important clinical utility for genetic counseling for eating disorders.

All participants overestimated recurrence risks for daughters of a person with an eating disorder to develop the same condition themselves, and the vast majority also overestimated the chance for a son. Mean estimated chances for eating disorder recurrence in sons and daughters (43.0 and $57.6 \%$, respectively) were considerably higher than the 3-12\% empiric recurrence risk (Thornton et al., 2010). This phenomenon of overestimation of risk to first-degree relatives has been observed in the context of other psychiatric conditions (Austin et al., 2006; Austin \& Honer, 2004; Kalb et al., 2017). Though previous work has shown relations between perceived risk to children and childbearing decisions (Austin \& Honer, 2004), we detected no such relation in the current study (this could be attributable to sample size, as only 15 participants reported fewer or no children as a result of their eating disorder). Regardless, given that discussion of risk for illness recurrence is an important component of genetic counseling, these data showing widespread overestimation of risk support the notion that genetic counseling could be useful for people with eating disorders.

It is important to note that genetic counseling differs from psychoeducational programming in two fundamental ways: (1) while psychoeducation may include information about genetic/environmental factors contributing to the condition affecting the family, such information is not typically the primary focus (Austin \& Honer, 2007); and (2) psychoeducation tends to be group based and more didactic in nature, whereas genetic counseling is a deeply personalized bidirectional exchange that focuses on counseling around the information provided, rather than the simple delivery of information, and tends to be delivered for an individual, couple, or family unit rather than larger groups (Bulik, Doyle, \& Austin, 2019).

Theoretically, genetic counseling could be implemented for individuals with eating disorders via a variety of models: for example, it could potentially be delivered by psychiatrists or psychologists, or by specialist trained nurses, or genetic counselors. However, research shows that healthcare providers other than genetic counselors (e.g., psychiatrists) often lack time and/or confidence and expertise to 
engage in the kinds of more in depth discussions about the role of genetics that are often required in order to meet patients' needs once the topic is opened for discussion (Abbate et al., 2014; Finn et al., 2005). This raises the possibility that there may be value in an interdisciplinary care approach, in which genetic counselors are integrated into eating disorder treatment teams (Austin, Inglis, \& Hadjipavlou, 2014), or that referring patients to genetic counseling services for the specific indication of an eating disorder may be worthwhile (e.g., by finding a genetic counselor in the teams local area through www.findageneticcounselor.com). Our data suggest that this is rarely happening at present, only 8 participants reported having received genetic counseling, and none of these sessions were for the indication of an eating disorder.

More participants perceived only benefits associated with genetic testing (most commonly the possibility of early identification and intervention) than only risks (most commonly fatalism or false reassurance) despite only a moderate degree of interest in genetic testing. Overall, there was less interest in genetic testing than other studies have found when looking at other psychiatric conditions, such as bipolar disorder, schizophrenia, major depression, and anxiety disorder (Austin et al., 2006; DeLisi \& Bertisch, 2006; Green et al., 2009; Laegsgaard, Kristensen, \& Mors, 2009; Meiser et al., 2005, 2007, 2008; Mitchell et al., 2010; Trippitelli, Jamison, Folstein, Bartko, \& DePaulo, 1998; Wilhelm et al., 2009). This could possibly be because we were asking individuals who had already developed an eating disorder, as opposed to their relatives, so they were less interested in testing to determine their genetic risk.

\section{1 | Limitations}

The participants in this study were primarily well-educated white women. Given the nature of the study, participants were also potentially highly motivated to participate in eating disorder research and more interested in new services for eating disorders since they were recruited through eating disorder online forums, support organizations, and blogs. Also, we have no way of estimating response rate, and though the ED100K has been validated for online administration (Thornton et al., 2018), there may be discrepancies between reported diagnoses and those established by a clinician. Though we found no significant relationship between participants' perceptions of the contribution of genetics to the etiology of eating disorders and whether or not they had a family history of an eating disorder, the effect size was small-medium, suggesting that the lack of statistical significance could be due to sample size. Given the size, self-selected nature, and relatively narrow demographic profile of our sample, our data may not be broadly generalizable, but serves to pave the way for future larger studies.

\section{2 $\quad$ Conclusions}

We found that most of the individuals with eating disorders who participated in this study were interested in accessing genetic counseling, and that they anticipated feeling decreased guilt, shame, and stigma as a result of receiving genetic counseling. Given the burdens associated with guilt, stigma, and shame for people who live with eating disorders, and the manner in which these factors impair people's help seeking behavior, we suggest that studies examining the impact of actual genetic counseling for people with eating disorders are needed.

\section{ACKNOWLEDGMENTS}

The authors thank Scott Richter, PhD and Romesh Arachchige for assistance with the statistical analyses; and Laura Thornton, PhD for access to and assistance with the ED100K. This study was funded through a grant provided by the National Society of Genetic Counselors' Psychiatric Special Interest Group. Extra thanks to Families Empowered and Supporting Treatment of Eating Disorders, June Alexander, Laura Collins Lyster-Mensh, National Eating Disorders Association, and Project HEAL for sharing the study with their communities. JA was supported by the Canada Research Chairs Program, and BC Mental Health and Substance Use Services.

\section{CONFLICT OF INTEREST}

C. B.-Shire: grant recipient and Scientific Advisory Board member, Idorsia: Consultant, Pearson: author and royalty recipient. J. A.-recipient of an investigated initiated grant from Pfizer.

\section{DATA AVAILABILITY STATEMENT}

The data that support the findings of this study are available on request from the corresponding author (LD). The data are not publicly available due to privacy or ethical restrictions.

\section{ORCID}

Cynthia M. Bulik (D) https://orcid.org/0000-0001-7772-3264

Sarah J. Hart (D) https://orcid.org/0000-0003-0974-3209

Jehannine Austin (DD https://orcid.org/0000-0003-0338-7055

\section{REFERENCES}

Abbate, K. J., Chung, W. K., Marder, K., Ottman, R., Taber, K. J., Leu, C.-S., \& Appelbaum, P. S. (2014). Psychiatrists' views of the genetic bases of mental disorders and behavioral traits and their use of genetic tests. Journal of Nervous and Mental Disease, 202, 530-538.

Akey, J. E., Rintamaki, L. S., \& Kane, T. L. (2013). Health belief model deterrents of social support seeking among people coping with eating disorders. Journal of Affective Disorders, 145(2), 246-252. https://doi.org/ 10.1016/j.jad.2012.04.045

Andrighetti, H., Semaka, A., Stewart, S. E., Shuman, C., Hayeems, R., \& Austin, J. (2016). Obsessive-compulsive disorder: The process of parental adaptation and implications for genetic counseling. Journal of Genetic Counseling, 25(5), 912-922. https://doi.org/10.1007/s10897015-9914-9

Arcelus, J. (2011). Mortality rates in patients with anorexia nervosa and other eating disorders: A meta-analysis of 36 studies. Archives of General Psychiatry, 68(7), 724-731. https://doi.org/10.1001/archgenpsychiatry.2011.74

Austin, J. C., \& Honer, W. (2004). The potential impact of genetic counseling for mental illness: Potential impact of genetic counseling. Clinical Genetics, 67(2), 134-142. https://doi.org/10.1111/j.1399-0004.2004.00330.x

Austin, J. C., \& Honer, W. G. (2007). The genomic era and serious mental illness: A potential application for psychiatric genetic counseling. Psychiatric Services, 58(2), 254-261. 
Austin, J. C., \& Honer, W. G. (2008). Psychiatric genetic counselling for parents of individuals affected with psychotic disorders: A pilot study. Early Intervention in Psychiatry, 2(2), 80-89. https://doi.org/10.1111/j. 1751-7893.2008.00062.x

Austin, J. C., Smith, G. N., \& Honer, W. G. (2006). The genomic era and perceptions of psychotic disorders: Genetic risk estimation, associations with reproductive decisions and views about predictive testing. American Journal of Medical Genetics Part B: Neuropsychiatric Genetics, 141B(8), 926-928. https://doi.org/10.1002/ajmg.b.30372

Austin, J. C., Inglis, A., \& Hadjipavlou, G. (2014). Genetic counseling for common psychiatric disorders: An opportunity for interdisciplinary collaboration. American Journal of Psychiatry., 171(5), 584-585.

Becker, A. E., Hadley Arrindell, A., Perloe, A., Fay, K., \& StriegelMoore, R. H. (2010). A qualitative study of perceived social barriers to care for eating disorders: Perspectives from ethnically diverse health care consumers. International Journal of Eating Disorders, 43(7), 633647. https://doi.org/10.1002/eat.20755

Bulik, C., Yilmaz, Z., \& Hardaway, A. (2015). Genetics and epigenetics of eating disorders. Advances in Genomics and Genetics, 5, 131. https:// doi.org/10.2147/AGG.S55776

Bulik, C., Doyle, L., \& Austin, J. (2019). Genetics of eating disorders, what the clinician needs to know. Psychiatric Clinics of North America, 42(1), 59-73.

Costain, G., Esplen, M. J., Toner, B., Scherer, S. W., Meschino, W. S., Hodgkinson, K. A., \& Bassett, A. S. (2014). Evaluating genetic counseling for individuals with schizophrenia in the molecular age. Schizophrenia Bulletin, 40(1), 78-87. https://doi.org/10.1093/ schbul/sbs138

Crisafulli, M. A., Von Holle, A., \& Bulik, C. M. (2008). Attitudes towards anorexia nervosa: The impact of framing on blame and stigma. International Journal of Eating Disorders, 41(4), 333-339. https://doi.org/10. 1002/eat.20507

DeLisi, L. E., \& Bertisch, H. (2006). A preliminary comparison of the hopes of researchers, clinicians, and families for the future ethical use of genetic findings on schizophrenia. American Journal of Medical Genetics Part B: Neuropsychiatric Genetics, 141B(1), 110-115. https://doi.org/ 10.1002/ajmg.b.30249

Duncan, L., Yilmaz, Z., Gaspar, H., Walters, R., Goldstein, J., Anttila, V., ... Bulik, C. M. (2017). Significant locus and metabolic genetic correlations revealed in genome-wide association study of anorexia nervosa. American Journal of Psychiatry, 174(9), 850-858. https://doi.org/10.1176/ appi.ajp.2017.16121402

Easter, M. (2014). Interpreting genetics in the context of eating disorders: Evidence of disease, not diversity. Sociology of Health \& IIIness, 36(6), 840-855. https://doi.org/10.1111/1467-9566.12108

Erickson, J. A., Kuzmich, L., Ormond, K. E., Gordon, E., Christman, M. F., Cho, M. K., \& Levinson, D. F. (2014). Genetic testing of children for predisposition to mood disorders: Anticipating the clinical issues. Journal of Genetic Counseling, 23(4), 566-577. https://doi.org/10.1007/ s10897-014-9710-y

Fairburn, C., \& Harrison, P. (2003). Eating disorders. The Lancet, 361(9355), 407-416.

Finn, C. T., Wilcox, M. A., Korf, B. R., Blacker, D., Racette, S. R., Sklar, P., \& Smoller, J. W. (2005). Psychiatric genetics: A survey of psychiatrists' knowledge, opinions, and practice patterns. Journal of Clinical Psychiatry, 66, 821-830.

Green, R. C., Roberts, J. S., Cupples, L. A., Relkin, N. R., Whitehouse, P. J., Brown, T., ... Farrer, L. A. (2009). Disclosure of APOE genotype for risk of Alzheimer's disease. New England Journal of Medicine, 361(3), 245254. https://doi.org/10.1056/NEJMoa0809578

Hippman, C., Ringrose, A., Inglis, A., Cheek, J., Albert, A. Y. K., Remick, R., ... Austin, J. C. (2016). A pilot randomized clinical trial evaluating the impact of genetic counseling for serious mental illnesses. The Journal of Clinical Psychiatry, 77(02), e190-e198. https://doi.org/10.4088/ JCP.14m09710
Hunter, M. J., Hippman, C., Honer, W. G., \& Austin, J. C. (2010). Genetic counseling for schizophrenia: A review of referrals to a provincial medical genetics program from 1968 to 2007. American Journal of Medical Genetics Part A, 152A(1), 147-152. https://doi.org/10.1002/ajmg.a. 33193

Inglis, A., Koehn, D., McGillivray, B., Stewart, S. E., \& Austin, J. (2015). Evaluating a unique, specialist psychiatric genetic counseling clinic: Uptake and impact. Clinical Genetics, 87(3), 218-224. https://doi.org/10. 1111/cge.12415

Kalb, F. M., Vincent, V., Herzog, T., \& Austin, J. (2017). Genetic counseling for alcohol addiction: Assessing perceptions and potential utility in individuals with lived experience and their family members. Journal of Genetic Counseling, 26(5), 963-970. https://doi.org/10.1007/s10897017-0075-x

Laegsgaard, M. M., Kristensen, A. S., \& Mors, O. (2009). Potential consumers' attitudes toward psychiatric genetic research and testing and factors influencing their intentions to test. Genetic Testing and Molecular Biomarkers, 13(1), 57-65.

Lyus, V. L. (2007). The importance of genetic counseling for individuals with schizophrenia and their relatives: Potential clients' opinions and experiences. American Journal of Medical Genetics Part B: Neuropsychiatric Genetics, 144B(8), 1014-1021. https://doi.org/10.1002/ajmg.b. 30536

Meiser, B., Kasparian, N., Mitchell, P., Strong, K., Simpson, J., Tabassum, L., ... Schofield, P. R. (2008). Attitudes to genetic testing in families with multiple cases of bipolar disorder. Genetic Testing, 12 (2), 233-243.

Meiser, B., Mitchell, P. B., Kasparian, N. A., Strong, K., Simpson, J. M., Mireskandari, S., ... Schofield, P. R. (2007). Attitudes towards childbearing, causal attributions for bipolar disorder and psychological distress: A study of families with multiple cases of bipolar disorder. Psychological Medicine, 37(11), 1601-1611. https://doi.org/10.1017/ S0033291707000852

Meiser, B., Mitchell, P. B., McGirr, H., Van Herten, M., \& Schofield, P. R. (2005). Implications of genetic risk information in families with a high density of bipolar disorder: An exploratory study. Social Science \& Medicine, 60(1), 109-118. https://doi.org/10.1016/j.socscimed.2004.04.016

Mitchell, P. B., Meiser, B., Wilde, A., Fullerton, J., Donald, J., Wilhelm, K., \& Schofield, P. R. (2010). Predictive and diagnostic genetic testing in psychiatry. Psychiatric Clinics of North America, 33(1), 225-243. https:// doi.org/10.1016/j.psc.2009.10.001

Moldovan, R., McGhee, K. A., Coviello, D., Hamang, A., Inglis, A., Ingvoldstad Malmgren, C., ... Austin, J. C. (2019). Psychiatric genetic counseling: A mapping exercise. American Journal of Medical Genetics Part B: Neuropsychiatric Genetics, 180(8), 523-532. https://doi.org/10. 1002/ajmg.b.32735

Moldovan, R., Pintea, S., \& Austin, J. (2017). The efficacy of genetic counseling for psychiatric disorders: A meta-analysis. Journal of Genetic Counseling, 26(6), 1341-1347. https://doi.org/10.1007/s10897-0170113-8

Quaid, K. A., Aschen, S. R., Smiley, C. L., \& Nurnberger, J. I. (2001). Perceived genetic risks for bipolar disorder in a patient population: An exploratory study. Journal of Genetic Counseling, 10, 41-51.

Quinn, V., Meiser, B., Wilde, A., Cousins, Z., Barlow-Stewart, K., Mitchell, P. B., \& Schofield, P. R. (2014). Preferences regarding targeted education and risk assessment in people with a family history of major depressive disorder. Journal of Genetic Counseling, 23(5), 785795. https://doi.org/10.1007/s10897-013-9685-0

Resta, R., Biesecker, B. B., Bennett, R. L., Blum, S., Estabrooks Hahn, S., Strecker, M. N., \& Williams, J. L. (2006). A new definition of genetic counseling: National Society of genetic counselors' task force report. Journal of Genetic Counseling, 15(2), 77-83. https://doi.org/10.1007/ s10897-005-9014-3

Semaka, A., \& Austin, J. (2019). Patient perspectives on the process and outcomes of psychiatric genetic counseling: An "empowering 
encounter". Journal of Genetic Counseling, 28(4), 856-868. https://doi. org/10.1002/jgc4.1128

Steinhausen, H.-C., Jakobsen, H., Helenius, D., Munk-Jørgensen, P., \& Strober, M. (2015). A nation-wide study of the family aggregation and risk factors in anorexia nervosa over three generations: Family aggregation of anorexia nervosa. International Journal of Eating Disorders, 48 (1), 1-8. https://doi.org/10.1002/eat.22293

Strober, M., Freeman, R., Lampert, C., Diamond, J., \& Kaye, W. (2000). Controlled family study of anorexia nervosa and bulimia nervosa: Evidence of shared liability and transmission of partial syndromes. The American Journal of Psychiatry, 157(3), 393-401.

Thompson, C., \& Park, S. (2016). Barriers to access and utilization of eating disorder treatment among women. Archives of Women's Mental Health, 19(5), 753-760. https://doi.org/10.1007/s00737-016-0618-4

Thornton, L. M., Mazzeo, S. E., \& Bulik, C. M. (2010). The heritability of eating disorders: Methods and current findings. In R. A. H. Adan \& W. H. Kaye (Eds.), Behavioral neurobiology of eating disorders (Vol. 6 , pp. 141-156). Berlin Heidelberg: Springer. https://doi.org/10.1007/ 7854_2010_91

Thornton, L. M., Munn-Chernoff, M. A., Baker, J. H., Juréus, A., Parker, R., Henders, A. K., ... M, C. (2018). The anorexia nervosa genetics initiative (ANGI): Overview and methods. Contemporary Clinical Trials, 74, 6169. https://doi.org/10.1016/j.cct.2018.09.015

Trippitelli, C. L., Jamison, K. R., Folstein, M. F., Bartko, J. J., \& DePaulo, J. R. (1998). Pilot study on patients' and spouses' attitudes toward potential genetic testing for bipolar disorder. American Journal of Psychiatry, 155(7), 899-904. https://doi.org/10.1176/ajp.155.7.899

Watson, H. J., Yilmaz, Z., Thornton, L. M., Hübel, C., Coleman, J. R. I., Gaspar, H. A., ... Bulik, C. M. (2019). Genome-wide association study identifies eight risk loci and implicates metabo-psychiatric origins for anorexia nervosa. Nature Genetics, 51(8), 1207-1214. https://doi.org/ 10.1038/s41588-019-0439-2

Wilhelm, K., Meiser, B., Mitchell, P. B., Finch, A. W., Siegel, J. E., Parker, G., \& Schofield, P. R. (2009). Issues concerning feedback about genetic testing and risk of depression. British Journal of Psychiatry, 194(5), 404-410. https://doi.org/10.1192/bjp.bp.107.047514

\section{SUPPORTING INFORMATION}

Additional supporting information may be found online in the Supporting Information section at the end of this article.

How to cite this article: Michael JE, Bulik CM, Hart SJ, Doyle L, Austin J. Perceptions of genetic risk, testing, and counseling among individuals with eating disorders. Int J Eat Disord. 2020;53:1496-1505. https://doi.org/10.1002/eat. 23333 